\title{
Spinal anaesthesia with midazolam in the rat
}

\author{
Murat Bahar MD, Mathias L Cohen MB CHB, \\ Yelena Grinshpon MD, Michael Chanimov MD
}

\begin{abstract}
Purpose: This study examined in an animal model whether intrathecal midazolam, alone or with fentanyl, can achieve anaesthesia sufficient for laparotomy, comparable to lidocaine. Effects on consciousness and whether anaesthesia was segmental were also examined. The haemodynamic and respiratory changes were compared with those of intrathecal lidocaine or intrathecal fentanyl alone.
\end{abstract}

Methods: Sixty Wistar strain rats, with nylon catheters chronically implanted in the lumbar subarachnoid theca, were divided into six groups. Group I $(n=12)$ received $75 \mu$ intrathecal lidocaine $2 \%$. Group $2(n=12)$ received $75 \mu \mathrm{L}$ intrathecal midazolam $0.1 \%$. Group $3(n=12)$ received intrathecal $37.5 \mu \mathrm{L}$ midazolam $0.1 \%$. plus $37.5 \mu \mathrm{L}$ fentanyl $0.005 \%$. Group $4(n=12)$ received intrathecal $50 \mu \mathrm{L}$ fentanyl $0.005 \%$. Group $5(n=6)$ received $75 \mu \mathrm{L}$ midazolam $0.1 \% \mathrm{~N}$. Group $6(n=6)$ received halothane $0.6 \%$ in oxygen by inhalation.

Results: Both groups that received intrathecal midazolam, alone or combined with fentanyl, developed effective segmental sensory and motor blockade of the hind limbs and abdominal wall, sufficient for a pain-free laparotomy procedure. Neither of these groups, unlike the group that received intrathecal lidocaine, developed a reduction in blood pressure or change in heart rate at the time of maximal sensory or motor blockade. nor were there changes in the arterial blood gases or respiratory rate.

Conclusion: Midazolam, when injected intrathecally, produces reversible, segmental, spinally mediated antinociception, sufficient to provide balanced anaesthesia for abdominal surgery.

Objectif : Un modèle animal a servi à examiner si le midazolam sous-arachnoïdien seul ou avec du fentanyl pouvait produire une anesthésie comparable à celle de la lidocainne et suffisante pour une laparotomie. Les effets sur la conscience ainsi que les caractéristiques segmentaires de l'anesthésie ont aussi été étudiés. Les changements hémodynamiques et respiratoires ont été comparés à ceux de la lidocaine et du fentanyl sous-arachnoïdiens seuls.

Méthodes : Soixante rats de souche Wistar porteurs de cathéters sous-arachnoïdiens implantés ont été répartis entre six groupes. Le groupe $\mid(n=12)$ recevait $75 \mu \mathrm{L}$ de lidocaïne sous-arachnoïdienne, le groupe $2(n=12)$ recevait $75 \mu \mathrm{L}$ de midazolam sous-arachnoidien, le groupe $3(n=12)$ recevait $37.5 \mu \mathrm{L}$ de midazolam et $37.5 \mu \mathrm{L}$ de fentanyl $0,005 \%$ sous-arachnoidiens, le groupe $4(n=12)$ recevait $50 \mu \mathrm{L}$ de fentany $10,005 \%$ sous-arachnoïdien, le groupe $5(n=6)$ recevait $75 \mu \mathrm{L}$ de midazolam intraveineux, le groupe 6 recevait de l'halothane $0.6 \%$ en oxygène par inhalation.

Résultats : Les deux groupes qui avaient reçu du midazolam sous-arachnoïdien seul ou combiné au fentanyl ont eu une anesthésie efficace segmentaire sensitive et motrice du train postérieur et de la paroi abdominale suffisante pour une laparotomie. Aucun de ces groupes, contrairement au groupe qui avait reçu de la lidocaine sous-arachnoidienne, n'a présenté de chute de pression artérielle ou de changements de la fréquence cardiaque au moment du block sensitif et moteur maximum ni d'altérations de la gazométrie artérielle et de la fréquence respiratoire.

Conclusion : Le midazolam sous-arachnoïdien produit une bloc nociceptif réversible, segmentaire, d'origine rachidienne, suffisant pour procurer une anesthésie équilibrée et adéquate pour une chirurgie abdominale.

From the Department of Anaesthesiology, Assaf Harofeh, Medical Centre, Zerifin, Affiliated to the Sackler Faculty, of Medicine, Tel-Aviv Universiry, Tel-Aviv, Israel.

Address correspondence to: Murat Bahar MD, Department of Anacsthesiology, Assaf Harofeh Medical Centre, Zerifin 70300, Israel

TEL: 972-8-9779463; FAX: 972-8-9779502.

Accepted for publication October 13, 1996. 
$\mathrm{T}$

HE possibility that intrathecal benzodiapezines could influence a nociceptive system was suggested in 1975 , when Haefely $e t a l .^{1}$ and Costa $e t a l^{2}$ demonstrated that benzodiazepines interact with the GABA system. This interaction was confirmed by Tallman et al. who showed that the binding of benzodiazepine to its receptor is enhanced by GABA and that benzodiazepine, by also binding to GABA recognition sites, makes more free GABA available. ${ }^{3}$ It has also been shown that morphine analgesia is enhanced either by an increase in the concentration of GABA in the CNS, brought about by decreasing the degradation of GABA by inhibition of the enzyme GABA transaminase ${ }^{4,5}$ or by the administration of the GABA reactor agonist, miscimol. ${ }^{6}$ However, GABA possesses analgesic properties ${ }^{7}$ and is found in the dorsal root area in high concentration. ${ }^{8}$ Specific benzodiazepine receptors are present throughout the nervous system including the spinal cord., ${ }^{9,10}$ Benzodiazepine receptor agonists, by modulating GABA receptors, affect the transmission of nociceptive impulses at the spinal cord level, when this transmission has been depressed by opioid receptor activation. ${ }^{11}$ The introduction of an exogenous benzodiazepine into the CSF bathing the spinal cord, would enable this drug to reach these receptors in high concentration and also to have a pronounced effect on local GABA activity.

Studies in animals and subsequently in humans, published by the University of Leeds, have encouraged others to use midazolam by both the epidural and intrathecal routes for pain relief. ${ }^{2-14}$ Apart from a non-specific fibrotic response to the tubing of the implanted intrathecal catheter, no signs of neurotoxicity of midazolam on the spinal cord or the meninges were found in histological studies in the rat and rabbit, ${ }^{16,17}$ confirming previous reports on rats, ${ }^{18}$ and in rabbits. ${ }^{19}$ Since then, a report has been published on the successful use of midazolam injected epidurally for the relief of post-operative pain, after upper abdominal surgery in humans. ${ }^{30}$ Intrathecal midazolam has also been shown to be an effective treatment for chronic mechanical low back pain and free from side effects. ${ }^{14}$ A combination of intrathecal midazolam and morphine has been shown to relieve chronic pain due to skeletal metastases in man. ${ }^{20}$

The purpose of the present study was to examine in an animal model firstly, whether midazolam administered alone or combined with fentanyl, by the spinal subarachnoid route, can provide effective intra-operative anaesthesia, comparable with that produced by intrathecal lidocaine, and sufficient to permit laparotomy and intra-abdominal manipulation. We also examined whether the antinociception was segmental, the effect on the animal's state of consciousness, and compared any accompanying changes in haemodynamic and respiratory variables with those produced by intrathecal lidocaine and intrathecal fentanyl.

\section{Material and methods}

The study was conducted in accordance with the rules and recommendations of the Home Office of Great Britain. Approval for the study was granted by the Ethical Committee of the Assaf Harofeh Medical Center.

The experiments were performed on 60 male, Wistar strain rats, weighing between $250-300 \mathrm{~g}$, divided into six groups (Table I). Each rat was housed separately in its own cage. Four of these groups contained 12 animals and were given intrathecal injections of lidocaine $2 \%$, midazolam $0.1 \%$, midazolam $0.1 \%$ plus fentanyl $0.005 \%$ and fentanyl $0.005 \%$ alone, respectively. Each of these four groups was further subdivided into two subgroups of six animals; one for analgesia studies while the animals breathed room air, and the other for haemodynamic studies and arterial blood gas analysis, while the animals breathed halothane $0.6 \%$ in oxygen, sufficient to immobilize them and permit measurement of haemodynamic variables.

A fifth group (Group 5) of six animals, while breathing room air, received a bolus of midazolam ip in the same dose that was administered intrathecally to the animals in Group 2, $75 \mu \mathrm{L}$ midazolam $0.1 \%$ $\left(0.3 \mathrm{mg} \cdot \mathrm{Kg}^{-1}\right)$.

A sixth group (Group 6) six animals, constituted a control group for determining the haemodynamic changes induced by inhaling halothane $2 \%$ for approximately $10 \mathrm{~min}$ to perform arterial cannulation and, thereafter, halothane $0.6 \%$. They also underwent spinal cannulation but received no intrathecal or intravenous test substances. The haemodynamic measurements were commenced $\mathbf{1 5} \mathrm{min}$ after the reduction of the halothane concentration from $2 \%$ to $0.6 \%$.

\section{Spinal Cannulation}

The animals were anaesthetised with halothane $2 \%$ in oxygen, administered by mask insufflation. After positioning prone and shaving, the lumbar spine was aseptically cannulated with a nylon catheter, outer diameter $0.75 \mathrm{~mm}$, according to a previously described method for chronic cannulation of the lumbar intrathecal space in the rat. ${ }^{21}$ The correct location of the catheter tip in the subarachnoid space was verified by seeing cerebrospinal fluid issuing through the lumen of the catheter. This was confirmed 24 hr before the experiment and $24 \mathrm{hr}$ after its completion, by injecting a bolus of $35 \mu \mathrm{L}$ lidocaine $2 \%$, sufficient to cause tran- 
sient hind-limb paralysis. In a preliminary pilot study in the rat, intrathecal injection of $35 \mu \mathrm{L}$ lidocaine $2 \%$ cause paralysis of only the hind-limbs and lower half of the body, whereas intrathecal injection of $75 \mu \mathrm{L}$ lidocaine $2 \%$ caused both fore-and hind-limb paralysis "high spinal" anaesthesia. Twenty-four hours after implantation of the lumbar subarachnoid catheters, the animals were again anaesthetised with halothane $2 \%$ in oxygen, and the common carotid artery was exposed and cannulated for direct arterial blood pressure and heart rate measurements, and for taking arterial blood for blood gas analysis. After closure of the skin wound, the inspired halothane concentration was reduced to $0.6 \%$, and 15 min later the haemodynamic recordings were commenced. Blood pressure and heart rate variables were measured using a Gould P.E. 50 pressure transducer and a Space Lab monitor, while the animals continued to breathe $0.6 \%$ halothane in oxygen. These constituted the base line measurements for determining the subsequent variations in haemodynamic values after injecting the intrathecal test-substances. Systolic and diastolic blood pressures and heart rate were measured, and recorded, every minute for one hour in six of the rats in each of the four groups, that received the intrathecal injections of the test-substances, and also in the six animals in the control groups (Group 6), who continued to inhale halothane $0.6 \%$ in oxygen, but received no intrathecal injection of any test-substance.

\section{Intrathecal injection, technique}

During the experiment $75 \mu \mathrm{L}$ of the three test substances - lidocaine $2 \%$; midazolam $0.1 \%$; and $37.5 \mathrm{ml}$ midazolam $0.1 \%$ plus $37.5 \mathrm{ml}$ fentanyl $0.005 \%$, were injected. In the case of fentanyl given alone (Group 4), a volume of $50 \mu \mathrm{L}$ was chosen because, in a preliminary pilot study, $75 \mu \mathrm{L}$ fentanyl $0.005 \%$ injected intrathecally produced respiratory depression and arrest. The volume of midazolam $0.1 \%$ that was selected was identical to the volume of lidocaine $2 \%$ which, when injected intrathecally, produced transient paralysis of both hindand fore-limbs of the animals.
The concentration of midazolam $0.1 \%$ for intrathecal injection was chosen, according to a preliminary pilot study, as being injectable through the nylon catheter without excessive pressure because of its viscosity. Furthermore, it is midway between the lower and higher concentrations employed by other workers in previous studies. ${ }^{15,22}$ The subarachnoid injections were all given at a speed of $20 \mu \mathrm{L} \cdot \mathrm{l}^{-1} \mathrm{~min}$. This speed of injection is important for the reproducibility of the results; faster injection promotes greater cephalad spread. (Table I).

\section{Respiratory Function}

Respiratory function was evaluated by observation and counting the respiratory rate with a stop-watch, every two minutes for the first $10 \mathrm{~min}$, and every five minutes thereafter, for the next hour. Arterial blood was sampled from the carotid artery cannula immediately before, one hour after, and $24 \mathrm{hr}$ after the intrathecal injection.

\section{Antinociception and Motor Power Studies}

(I) Antinociception in the segmental dermatomes was evaluated by the squeak-withdrawal response to the haemostat-pinch test. ${ }^{23}$ The area to be tested was first lightly touched with the haemostat to distinguish between the animal's response to touch and to pain caused by pinching. An area of $3 \mathrm{~mm}$ was then lightly pinched in the jaws of the haemostat and the pressure gradually increased until the first ratchet of the haemostat was engaged. At any stage of this procedure, should the animal show signs of discomfort or squeak, the pressure was released and the result recorded as "no antinociception." Should there be no response to pinching and the animal remained quiet, antinociception was recorded as "present."

Sensation was tested in five different sites at three to five minute intervals: over the mid-portion of the tail, dorsum of the hind-limb paw, lateral wall of the mid-abdomen, dorsum of the fore-limb paw, and over the pinna of the ear.

TABLE 1 Experimental Groups

\begin{tabular}{llllll}
\hline Group & $n$ & Drug & Concentration & Volume & Route \\
\hline 1 & 112 & Lido & $2 \%$ & $75 \mu \mathrm{L}$ & it \\
2 & 12 & Mid & $0.1 \%$ & $75 \mu \mathrm{L}$ & it \\
3 & 12 & Mid + Fent & $0.1 \% / 0.005 \%$ & $37.5 \mu \mathrm{L} / 37.5 \mu \mathrm{L}$ & it \\
4 & 12 & Fent & $0.005 \%$ & $50 \mu \mathrm{L}$ & it \\
5 & 6 & Mid & $0.1 \%$ & $75 \mu \mathrm{L}$ & iv \\
6 & 6 & $\mathrm{Hal} \mathrm{in} \mathrm{O}_{2}$ & $0.6 \%$ & $0.5 \mathrm{~L} \cdot \mathrm{min}^{-1}$ & inbal \\
\hline
\end{tabular}

(Lido - lidocaine, mid - midazolam, fent - fentanyl, hal - halothane, it - intrathecal, ip - intravenous, inhal - inhalation.) 


\section{(ii) Motor power of the limbs:}

Motor power in the hind- and fore-limbs was evaluated by noting whether the animal could stand on all four limbs, whether it dragged the hind-limbs or was unable to stand.

(iii) Antinociception and muscle relaxation of the abdominal wall were evaluated by the ability to perform a $3 \mathrm{~cm}$, low-paramedian laparotomy, withdraw a loop of bowel and replace it in the peritoneal cavity, and then close the laparotomy incision, without the animal resisting or showing any sign of pain or distress. This procedure was commenced only after establishing absence of sensation to the haemostat-pinch test over the lateral wall of the mid-abdomen and over the hind-limb paws and tail. Provision was made for the immediate administration of mask anaesthesia with halothane $2 \%$ in $\mathrm{O}_{2}$, should any of the animals react to pain when the result was recorded as "insufficient antinociception for laparotomy."

\section{Statistical Analysis}

In each experimental group the haemodynamic variables of blood pressure and heart rate and the respiratory rate and arterial blood gases are expressed as the mean \pm standard deviation and analysed for variance and statistical significance $(P<0.05)$.

\section{Results}

Group 1: Intrathecal injection of $75 \mu \mathrm{L}$ lidocaine $2 \%$ produced sensory blockade over the tail, hind-limbs, abdominal wall and fore-limbs within $3.5 \pm 0.12 \mathrm{~min}$. Paralysis of all four limbs became established at the same time as the sensory block, both disappearing gradually by $41.3 \pm 1.2 \mathrm{~min}$. Sensation over the ear pinna remained intact throughout. Sensory blockade and abdominal wall relaxation were adequate for laparotomy and bowel manipulation. The animals remained with their eyes open, but without squeaking, except when the ear pinna was pinched, when they would squeak or move their heads.

There was a decrease in both systolic and diastolic blood pressures $(P<0.01)$, two minutes after injection

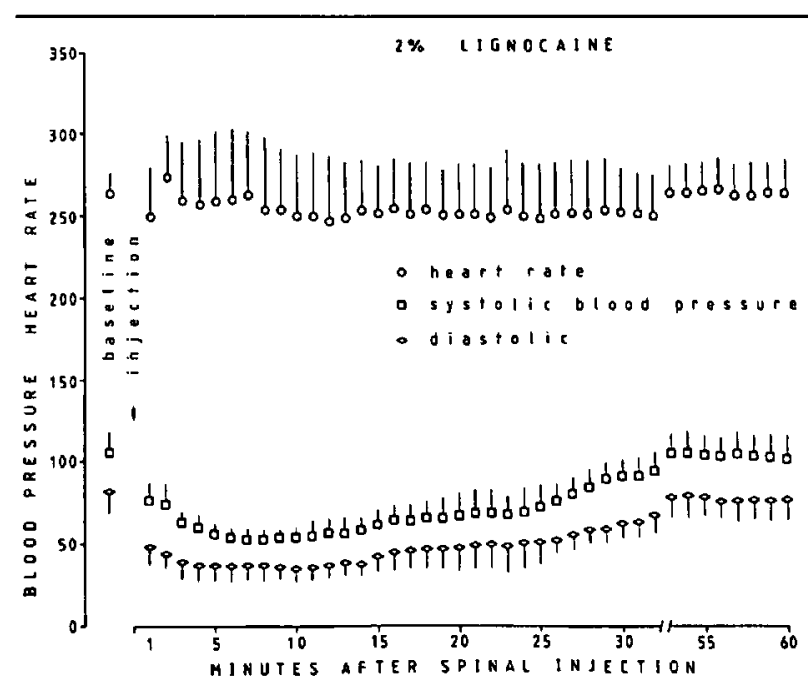

FIGURE 1 Hemodynamic changes following intrathecal injection of lidocaine $2 \%$.

of the intrathecal bolus, with a progressive recovery, commencing $15 \mathrm{~min}$ after the injection and a return to the pre-injection level by $39.8 \pm 1.6 \mathrm{~min}$ after the injection. There was no change in heart rate throughout the experimental period (Figure 1).

Respiratory Function: A mild, statistically insignificant reduction in respiratory rate occurred, gradually, from $90.0 \pm 7.0 \mathrm{bpm}$ to $79.3 \pm 8.8 \mathrm{bpm}$, over $45 \mathrm{~min}$ following the injection.

Arterial Blood Gases (ABG): There were no changes in the $A B G$ variables measured before, one hour and $24 \mathrm{hr}$ after the intrathecal injection of lidocaine (Table II).

Group 2: Intrathecal injection of $75 \mu L$ midazolam $0.1 \%$ : This produced sleep and a decrease in respiratory rate from $86.4 \pm 5.8$ to $67.3 \pm 5.1 \mathrm{bpm}(P<0.05)$, three and four minutes after the injection. Sensory block over the tail, hind-limbs, mid-abdomen and fore-limbs became apparent by $14 \pm 1$ min following the intrathecal injection. The haemostat-pinch test on the pinna of the ear produced movement of the head and opening of the eyes, indicating that the antinoci-

TABLE II Results summary

\begin{tabular}{llllll}
\hline Group & Sensory & Motor & Laparotomy & Haemodynamic & Respiratory \\
\hline & Deficit & Deficit & possible & Changes & Changes \\
1.Lido $i t$ & + & + & + & + & - \\
2.Mid it & + & + & + & - & - \\
3. Mid/Fent $i t$ & + & + & + & - & + \\
4. Fent & - & - & - & - & - \\
5. Mid ip & - & - & - & - & - \\
6. Hal inhal & - & - & - & - & - \\
\hline
\end{tabular}




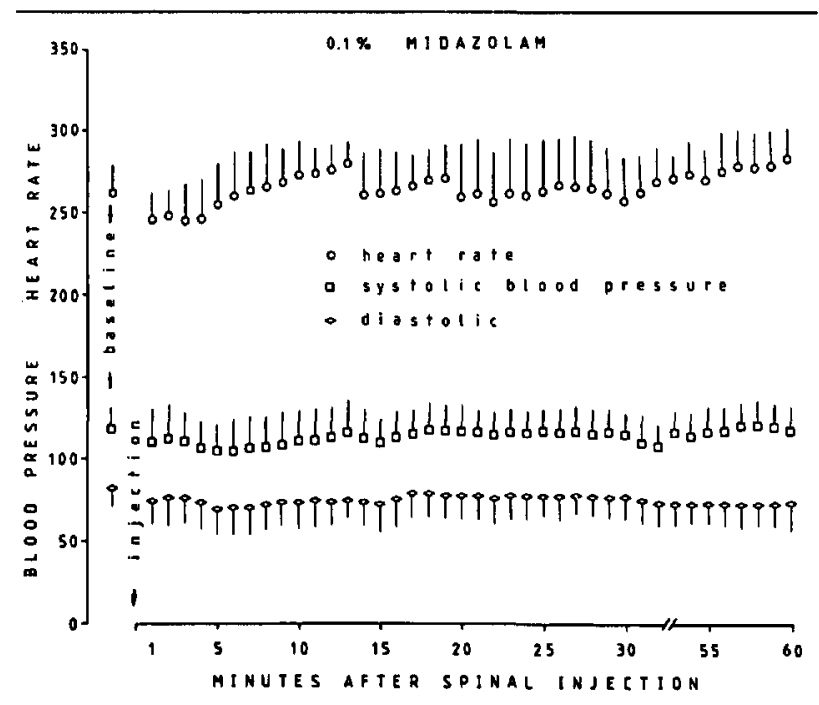

FIGURE 2 Hemodynamic changes following intrathecal injection of midazolam $0.1 \%$.

ception was segmental. By $14 \pm 1$ min, paralysis of both fore- and hind limbs was established and lasted $39.0 \pm 2.5 \mathrm{~min}$. Sensory blockade and relaxation of the abdominal wall were sufficient to permit pain-free laparotomy procedure at this time. By $87.3 \pm 7.8 \mathrm{~min}$ after the injection, all animals were awake and responsive to the haemostat pinch test. There was a statistically insignificant, transient reduction in systolic blood pressure, and no change in heart rate throughout the experiment (Figure 2).

Arterial Blood Gases ( $A B G$ ): There were no changes in the $A B G$ variables after the intrathecal injection of midazolam.

Group 3: Intrathecal injection of $37.5 \mu L$ midazolam $0.1 \%+37.5 \mu L$ fentanyl $0.005 \%$ : This produced sleep with a reduction in the respiratory rate from $86.8 \pm 6.1$ to $69.8 \pm 5.6 \mathrm{bpm}(P<0.05), 15 \mathrm{~min}$ after injection, and the respiratory rate remained at this level for 90 min. Sensory block became established over the tail, hind-limbs, mid-abdomen and fore-limbs by $7.8 \pm 0.8$ min after the intrathecal injection. Sensory blockade and abdominal wall relaxation were also present at this time and were sufficient to permit a pain-free laparotomy procedure. Sensory and motor blockade recovered gradually by $43.3 \pm 1.6 \mathrm{~min}$. By $84.9 \pm 3.4 \mathrm{~min}$, the animals were awake and moving spontaneously.

There were no haemodynamic variations in either systolic or diastolic blood pressure or heart rate (Figure 3). Arterial Blood Gases ( $A B G$ ): There were no changes in $\mathrm{ABG}$ variables.

Group 4: Intrathecal injection of $50 \mu \mathrm{L}$ fentanyl 10.005\%: This produced, in four of the six animals, an absence of

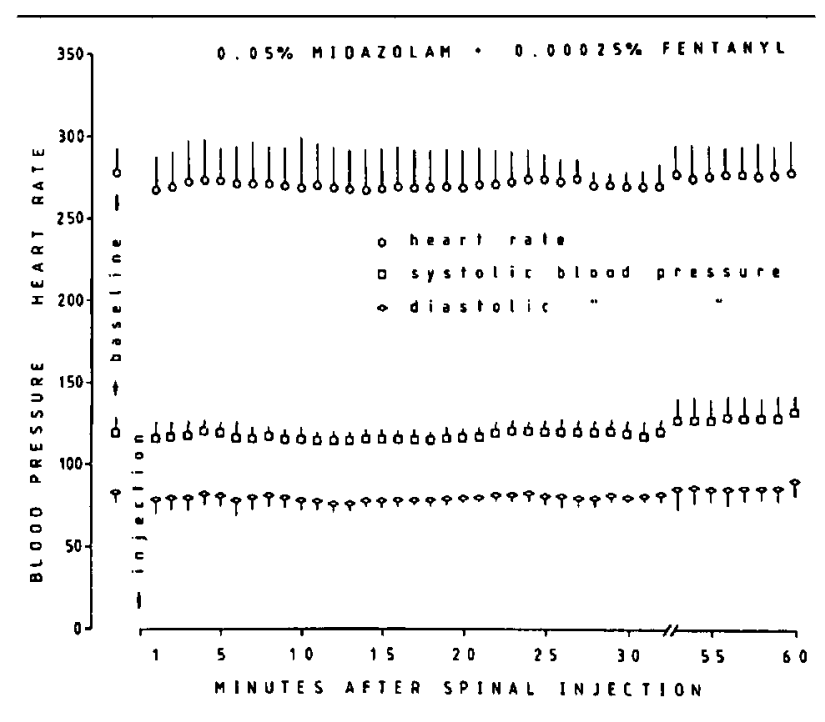

FIGURE 3 Hemodynamic changes following intrathecal injection of midazolam $0.1 \%$ and fentanyl $0.005 \%$.

response to the haemostat-pinch test over the tail and abdomen only. This commenced within $3.8 \pm 1.3 \mathrm{~min}$, and lasted $18.2 \pm 4.7 \mathrm{~min}$. They continued to respond over the hind-and fore-limbs and over the ear pinna. Two of the animals continued to respond to the pinch test over all the test-sites by withdrawal of the stimulated limb and tail, and over the ear pinna by squeaking or attempting to escape. In view of the lack of an antinociceptive response over the trunk and limbs in most of these animals, laparotomy was not attempted.

Haemodynamic studies. There were no changes in either the systolic or diastolic blood pressure, or heart rate (Figure 4).

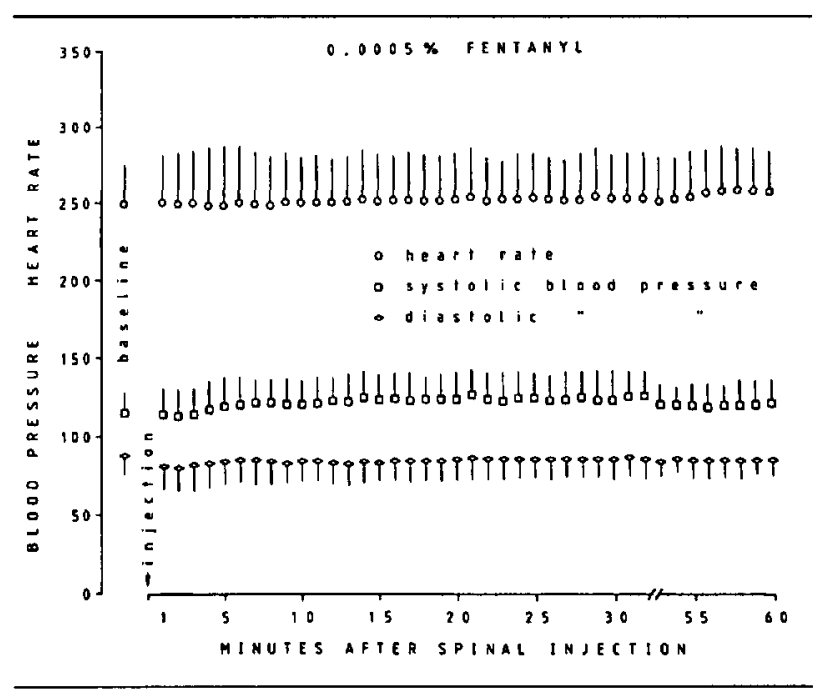

FIGURE 4 Hemodynamic changes following intrathecal injection of fentanyl $0.005 \%$. 


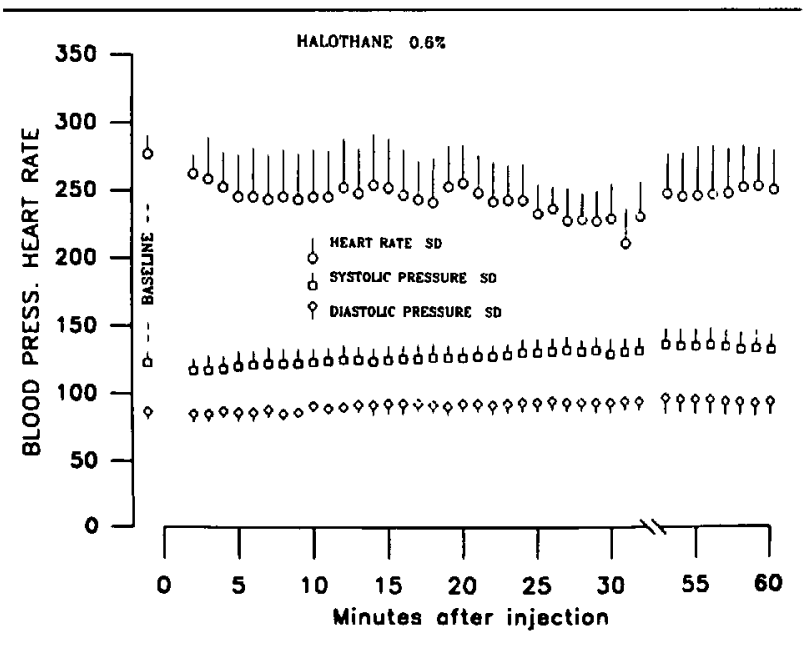

FIGURE 5 Haemodynamic changes following inhaling halothane $0.6 \%$ in oxygen

Respiratory rate: This decreased from $92.3 \pm 3.4$ to $85.3 \pm 18.6 \mathrm{bpm}$ within $20 \mathrm{~min}$, and returned to base line values by $45 \mathrm{~min}$ after the injection.

Arterial Blood Gases ( $A B G$ ): There were no changes in $A B G$ variables.

Group 5: Intravenous midazolam 0.1\%: The animals fell asleep after $1.8 \pm 0.3 \mathrm{~min}$, and remained so for $16.0 \pm 1.3 \mathrm{~min}$. Throughout this period, they continued to respond to the haemostat-pinch test by withdrawal of the stimulated limb, opening their eyes and attempting to escape. There was no change in respiratory rate or $\mathrm{ABG}$ variables.

Group 6: Halotbane 0.6\%: These animals were asleep, but showed occasional spontaneous movements. They all responded to the haemostat-pinch test by attempting to stand on both fore- and hind-limbs and also by trying to escape. The haemodynamic variables showed a progressive increase in systolic and diastolic blood pressure from $123.1 \pm 8.5 / 87 \pm 4.7 \mathrm{~mm} \mathrm{Hg}$ to $139.8 \pm 14.85 / 100.0$ $\pm 6.5 \mathrm{~mm} \mathrm{Hg}$, but this was not statistically significant. The heart rate decreased from $277.6 \pm 14.8$ to $230.9 \pm$ $29.8 \mathrm{~min}^{-1}$ at $33 \mathrm{~min}(P<0.05)$, and thereafter remained constant for the next 87 minutes (Figure 5). There was no change in $A B G$ variables.

Results in the six groups indicated the different outcomes: presence of a sensory deficit, motor deficit, ability to perform laparotomy and the accompanying haemodynamic and respiratory changes, are summarized in Table II.

All animals recovered completely and were fully active, mobile, and eating and drinking normally by the next day and during the subsequent week following the experiment.

\section{Discussion}

The results of our study in the rat show that in those animals receiving a lumbar intrathecal bolus of $75 \mu \mathrm{L}$ midazolam $0.1 \%$ alone, sleep was induced within three to four minutes of injection, but stimulation of the hind-limbs by the haemostat-pinch test continued to produce a withdrawal response. However, after $14 \mathrm{~min}$, effective motor and sensory blockade of the hindlimbs, as well as segmental antinociception and relaxation of the abdominal wall sufficient for a laparotomy procedure, were established. The group that received a lumbar intrathecal injection of $37.5 \mu \mathrm{L}$ midazolam $0.1 \%$ combined with $37.5 \mu \mathrm{L}$ fentanyl $0.005 \%$ developed sensory blockade and relaxation of the abdominal wall sufficient to permit laparotomy and intra-abdominal manipulation, as well as sensory and motor blockade of the hind-limbs within eight minutes. In neither of these two groups were any reductions in systolic or diastolic blood pressure, changes in heart rate, arterial blood gas variables or respiratory rate observed.

Benzodiazepines act in the brain and spinal cord on the GABA receptor complex, ${ }^{25}$ and not by blocking the transmission of sensory impulses through nerve fibers. ${ }^{26,27}$ Intrathecal midazolam has been shown to produce anti-nociceptive effects in $\operatorname{man}^{13}$ and is effective, by intrathecal injection, in relieving chronic mechanical low-back pain ${ }^{14}$ as well as for chronic pain due to metastatic bone tumors. ${ }^{20}$ The analgesic effect of midazolam by subarachnoid infusion, through a longterm lumbar intrathecal catheter, is described in a particularly difficult case of cancer pain management. ${ }^{21}$

It has also been reported to be effective by the epidural route in the treatment of acute post-operative somatic pain in adults ${ }^{28}$ and by the candal cpidural route in children for post-operative pain relief after inguinal herniorrhaphy and operations on the genitalia. ${ }^{29}$ Spinal opioids have been extensively used to supplement both regional and general anaesthesia in man and to provide post-operative analgesia, but have not been successful in providing adequate intra-operative analgesia when injected intraspinally alone. ${ }^{29}$ This is the first study to show that intrathecal midazolam can produce surgical anaesthesia in an animal model.

High spinal anaesthesia is a well recognized complication of intrathecal or epidural injection of local anaesthetic drugs. ${ }^{32,33}$ Although total spinal anaesthesia has been intentionally produced as part of a general anaesthetic technique, the sharp decrease in systemic blood pressure associated with this procedure has discouraged its adoption for wider use. ${ }^{34}$ Furthermore, cardio-respiratory arrest associated with unintentional high or total spinal anaesthesia is a complication demanding immediate resuscitative action. ${ }^{31}$ Intrathecal opioids do not 
block the sympathetic nervous system with a resulting decrease in systemic blood pressure, but can spread cephalad when injected into the lumbar region and may thus produce respiratory depression or arrest. ${ }^{35}$ The production, in our model, of segmental spinal anaesthesia accompanied by sedation, but without haemodynamic changes, by the intrathecal injection of midazolam with fentanyl, appears to be a promising addition to our existing anaesthetic armamentarium.

This is the first study to show that intrathecal midazolam can produce antinociception sufficient for surgery, similar to that provided by intrathecal lidocaine. Previously, intrathecal midazolam has been considered to produce an analgesic effect comparable with intrathecal opioids. ${ }^{23}$ However, we have demonstrated that a benzodiazepine, a non-opioid, and a non-analgesic when given by normal, non-spinal routes, and a substance without local anaesthetic action, when injected intrathecally provides segmental spinal anticociception sufficient to permit laparotomy. This "balanced anaesthesia," if it can also be produced in man without haemodynamic change, could find wide application in abdominal and lower limb surgery.

\section{Acknowlegements}

We would like to thank Dr. Alexander Klein from the Department of Mathematics at Bar-Ilan University, Israel, for the Statistical Analysis. We are especially indebted to Anji Agajani and Jane Geva for their secretarial assistance.

\section{References}

1 Haefely W, Kulcsar A, Möbler H, Pieri L, Polc P, Schaffner $R$. Possible involvement of GABA in the central actions of benzodiazepines. In: Costa $\mathrm{E}$, Greegard $P$ (Eds.). Mechanism of Action of Benzodiazepines. New York: Raven Press, 1975: 131-51.

2 Costa E, Guidotti A, Mao CC, Suria $A$. New concepts on the mechanism of action of benzodiazepines. Life Sciences $1975 ; 17$ : 167-86.

3 Tallman JF, Thomas JW, Gallager DW. GABAergic modulation of benzodiazepines binding site sensitivity. Nature (Lond) $1978 ; 274: 383-5$.

4 Guidotti $A$, Toffano $G$, Costa $E$. An endogenous protein modulates the affinity of GABA and benzodiazepine receptors in rat brain. Nature (Lond) 1978; 275: 553-5.

5 Contreras E, Tamayo $L$, Quijada $L$. Effects of the irreversible inhibition of GABA transaminase upon some morphine effects. Neuropharmacology 1979; 18: 309-13.

6 Biggio $G$, Bella DD, Frigeni V, Guidotti A. Potentiation of morphine analgesia by muscimol. Neuropharmacology 1977; 16: 149-50.
7 Buckett WR. Induction of analgesia and morphine potentiation by irreversible inhibitors of GABAtransaminase. $\mathrm{Br}$ J Pharmacol 1980; 68: 129-30

8 Buckett WR. Irreversible inhibitors of GABA transaminase induce antinociceptive effects and potentiate morphine. Neuropharmacology 1980; 19: 715-22.

9 Mohler $H$, Okada T. Benzodiazepine receptor: demonstration in the central nervous system. Science 1977; 198: 849-51.

10 Squires RF, Braestrup C. Benzodiazepine receptors in rat brain. Nature 1977; 266: 732-4.

11 Kuriyama K, Toneda $\Upsilon$. Morphine induced alterations of yaminobutyric acid and taurine contents and L-glutamate decarboxylase activity in rat spinal cord and thalamus: possible correlates with analgesic action of morphine. Brain Res 1978; 148: 163-79.

12 Goodchild CS, Serrao JM. Intrathecal midazolam in the rat: evidence for spinally-mediated analgesia. $\mathrm{Br} J$ Anaesth 1987; 59: 1563-70.

13 Goodchild CS, Noble J. The effects of intrathecal midazolam on sympathetic nervous system reflexes in man a pilot study. Br J Clin Pharmacol 1987; 23: 279-85.

14 Serrao JM, Marks RL, Morley SJ, Goodchild CS. Intrathecal midazolam for the treatment of chronic mechanical low back pain: a controlled comparison with epidural steroid in a pilot study. Pain 1992; 48: 5-12.

15 Moreau $J-L$, Pieri $L$. Effects of an intrathecally administered benzodiazepine receptor agonist, antagonist and inverse agonist on morphine-induced inhibition of a spinal nociceptive reflex. Br J Pharmacol 1988; 93: 964-8.

16 Auroy $P$, Schoeffler $P$, Maillot $C$, Haberer $J$, Woda $A$. Tolérance intrathécal du midazolam: etude histologique. Ann Fr Anesth Reanim 1988; 7: 81-2.

17 Schoeffler $P$, Auroy P, Bazin JE, Taxi J, Woda A. Subarachnoid midazolam: histologic study in rats and report of its effect on chronic pain in humans. Reg Anesth 1991; 16: 329-32.

18 Serrao JM, Mackenzie JM, Goodcbild CS, Gent JP. Intrathecal midazolam in the rat: an investigation of possible neurotoxic effects. Eur J Anaesthesiol 1990; 7: 115-22.

19 Madsen JB, Jensen FM, Crawford ME, Toftdabl DB. Catheterization of the epidural space in the rabbit. Neuropathological effects of epidural meptazinol and midazolam. Pain 1990; 5: S124.

20 Yáez $A$, Peleteiro $R$, Camba $M A$. Intrathecal administration of morphine, midazolam and both in four patients with chronic pain. (Spanish) Rev Esp Anestesiol Reanim 1992; 39: 40-2.

21 Aguilar JL, Espachs P, Roca G, Samper D, Cubells C, $V i d a l F$. Difficult management of pain following sacro- 
coccygeal chordoma: 13 months of subarachnoid infusion. Pain 1994; 2: 317-20.

22 Bahar $M$, Rosen $M$, Vickers $M D$. Chronic cannulation of the intradural or extradural space in the rat. $\mathrm{Br} \mathrm{J}$ Anaesth 1984; 56: 405-10.

23 Niv D, Whitwam JG, Lob L. Depression of nociceptive sympathetic reflexes by the intrathecal administration of midazolam. Br J Anaesth 1983; 55: 541-7.

24 Yaksh TL, Rudy TA. Studies on the direct spinal action of narcotics in the production of analgesia in the rat. J Pharmacol Exp Ther 1977; 202: 411-27.

25 Yanez A, Sabbe MB, Stevens CW, Yaksh TL. Interaction of midazolam and morphine in the spinal cord of the rat. Neuropharmacology 1990; 29: 359-64.

26 Edwards M, Serrao JM, Gent JP, Goodchild CS. On the mechanism by which midazolam causes spinally mediated analgesia. Anesthesiology 1990; 73: 273-7.

27 Clavier N, Lombard $M-C$, Besson J-M. Benzodiazepines and pain: effect of midazolam on the activities of nociceptive non-specific dorsal horn neurons in the rat spinal cord. Pain 1992; 48: 61-71.

28 Nishiyama $T$, Odaka $\Upsilon$, Hirasaki A, Seto $K$. Epidural midazolam for treatment of postoperative pain. (Japanese) Masui 1991; 40: 1353-8.

29 Naguib M, El Gammal $M$, Elbattab YS, Seraj $M$. Midazolam for caudal analgesia in children: comparison with caudal bupivacaine. Can J Anaesth 1995; 42: 758-64.

30 Stenseth $R$, Sellevold $O$, Breivik $H$. Epidural morphine for postoperative pain: experience with 1085 patients. Acta Anaesthesiol Scand 1985; 29: 148-56.

31 Knill RL. Cardiac arrests during spinal anesthesia: unexpected? (Letter) Anesthesiology 1988; 69: 629.

32 Gild $W$, Crilley $P$. Sudden cardiac arrest during epidural anesthesia (Letter). Anesthesiology 1990; 73: 1296.

33 Evans TI. Total spinal anaesthesia. Anaesth Intensive Care 1974; 2: 158-63.

34 Caplan RA, Ward RJ, Posner $K$, Cheney FW. Unexpected cardiac arrest during spinal anesthesia: a closed claims analysis of predisposing factors. Anesthesiology 1988; 68: 5-11.

35 Gustafson LL, Schildt B, Jacobsen $K$. Adverse effects of extradural and intrathecal opiates: report of a nationwide survey in Sweden. Br J Anaesth 1982; 54: 479-86. 